DOI: 10.34220/DSPPD2021_19-28

УДК 37.012, 37.022

Гришин Андрей Александрович, кандидат философских наук, старший преподаватель, Воронежский государственный лесотехнический университет имени Г.Ф. Морозова

\author{
ИНФОРМАЦИОННОЕ ПРОЕКТИРОВАНИЕ УЧЕБНОЙ \\ ДЕЯТЕЛЬНОСТИ ОБУЧАЮЩИХСЯ В ОНТОЛОГИЯХ ВОЛЕВОГО \\ УСИЛИЯ И ИНТЕРТЕЙМЕНТА
}

\title{
INFORMATION DESIGN OF LEARNING ACTIVITIES OF STUDENTS IN ONTOLOGIES OF WILLED EFFORT AND ENTERTAINMENT
}

\begin{abstract}
Аннотация: В статье подвергаются детальному анализу концепции организации учебного процесса в предметных рамках волевого развития и в предметных рамках эмоционального отвлечения. Первое рассматривается в алгоритмическом смысле, в то время как второе опосредуется онтологической системой эвристического содержания и направленности. Проблема соотношениях двух компонентов учебной деятельности обучающихся эксплицируется в феномене трансформации классической модели образования в цифровое и в техническое интертеймент-обеспечение учебного процесса. Последнее мыслится как необходимое и обусловленное кризисами современного общества, ориентация же исследования делается возможной вследствие переориентации мышления обучающихся [!] с феноменального (чувственного) возможного как интертеймент [в учебном процессе] на формирование волевого усилия: при этом мыслимое в эвристической онтологии развлечение (entertainment) с точки зрения целеполагания самих обучающихся опосредуется экзистенциальным порывом, обозначаемым через philosophia moralis или через когнитивное снятие [Aufhebung/Sublation «по Гегелю»].

Abstract: The article presents a detailed analysis of the concept of organizing the educational process in the subject framework of volitional development and in the subject framework of emotional distraction.
\end{abstract}

Ключевые слова: информационное проектирование, волевое усилие, когнитивное снятие, учебный процесс, интертеймент, логическая абстракция.

Keywords: information design, volitional effort, cognitive withdrawal, learning process, interteiment, logical abstraction

\footnotetext{
${ }^{\circ}$ Гришин А.А., 2021
} 


\section{Проблемы цифровизации учебного процесса}

Основной проблемой в современной системе общего и высшего образования в Российской Федерации является проблема качественного развития абстрактно-логического мышления обучающихся с последующей профильной ориентацией последних в сферу естественно-научного и гуманитарного знания. Реализовать поставленную задачу можно подвергнув концептуализации мышление современного человека с необходимостью взаимодействующего с аппаратными средствами, такими как смартфоны, компьютеры, банкоматы и другие технические устройства, обладающие графическими интерфейсами. Трудность состоит в том, что не всегда при использовании технических устройств человек задействует абстрактнологическое мышление. Функционально вовлечённые в образовательную деятельность тинэйджеры и студенты, используют выше обозначенные графические интерфейсы для получения феноменально (чувственно) окрашенного удовольствия, способствующего эмоциональной разрядке. Такие сервисы как TikTok, Instagram, ВКонтакте и Telegram, став кроссплатформенными обеспечивают при этом особое понимания бытия среди их пользователей не столько содержательно, сколько формально: перцептивно формуя оптическую модель восприятия окружающего мира. Следует заметить, что стиль мышления формируемый выше обозначенными сервисами диктует и сам способ проведения учебного процесса, поскольку в рамках последнего следует обращаться к формально-логическим законам. Превалирование феноменального опыта над опытом построения логических абстракций не сулит ничего хорошего ни для тинэйджеров, ни для студентов высших учебных заведений. Однако позволить обучиться последним логическому мышлению в интерактивном формате организации учебного процесса достаточно проблематично, поскольку этому способствовала классическая модель образования, которая осуществляла перекодирование как сенсорной системы человека, так и его нервной системы. В интерактивном формате обучения речь идёт о получении качественного феноменального опыта, который необходим при обучении только в том случае, когда мышление обучающиеся фактически перегружено той или иной информации по излагаемому курсу. Графически это отображается следующим образом (см. рис. 1). 


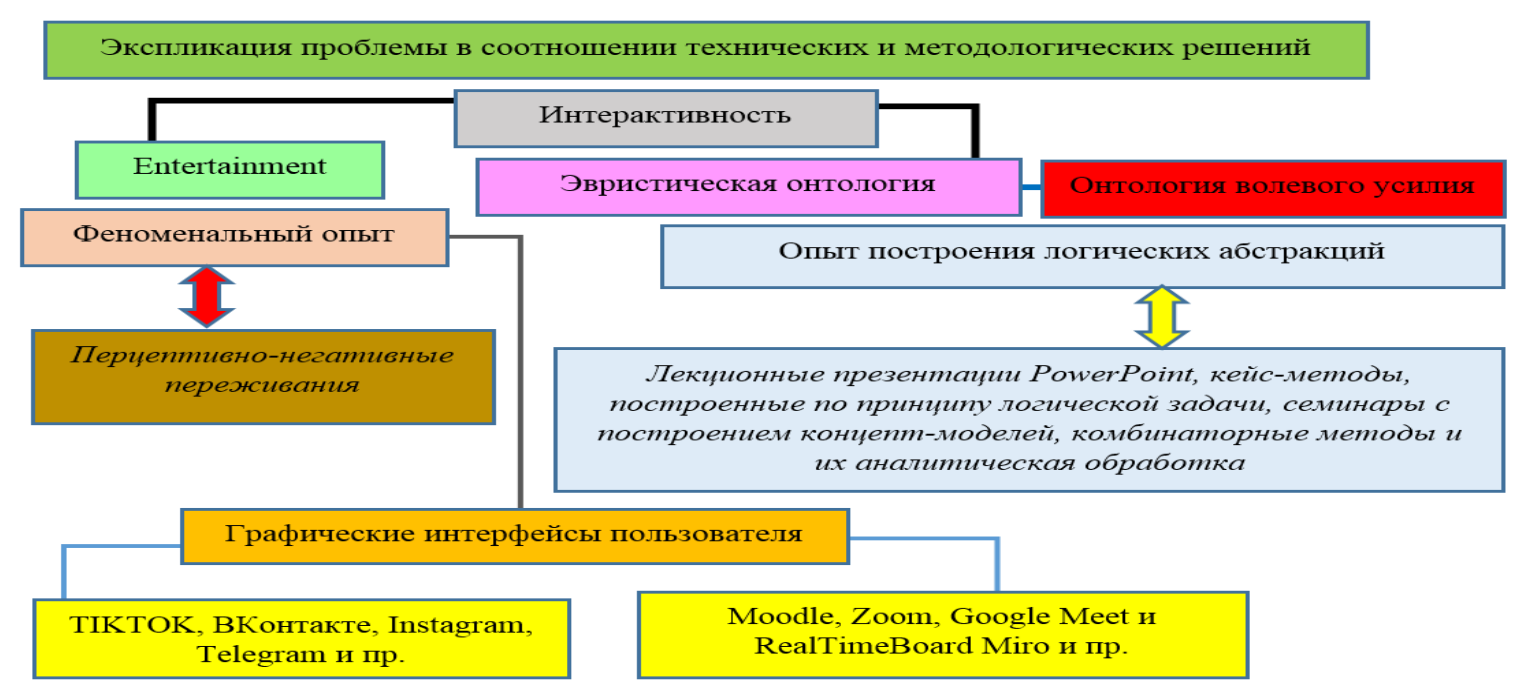

\section{Рисунок 1}

Первоначально, информация по излагаемому в процессе обучения курсу должна совмещаться с тем стилем мышления обучающихся к какому они привыкли в сети Интернет с той целью, чтобы перекодирование сенсорной и нервной систем в процессе обучения происходило в максимально комфортных для последних условий. Экспликация же логического способа формализации информации в рамках излагаемого курса не должна навязываться, но актуализироваться как сопутствующая по той простой причине, что только таким образом можно сформировать доверительную атмосферу в процессе обучения между кураторами учебной деятельности и обучающимися. Таким образом, феномен интертеймента в процессе учебной деятельности должен облекаться в ненавязчивую формально-логическую оболочку, причинноследственная связь в рамках которой должна определяться не извне, но личностно самими обучающимися. Следует отметить, что соотношение эвристических моделей обучения с классическими моделями интерактивного взаимодействия с аудиторией в ходе учебного процесса является общемировой тенденцией. Например, в связи с переходом на дистанционный формат обучения, вследствие пандемии коронавирусной инфекции, вызванной коронавирусом SARS-CoV-2, как и с обратным возвращением в естественный формат обучения, аналитиками Министерства Просвещения Российской Федерации, аналитиками Министерства науки и высшего образования Российской Федерации, а также российскими учёными были сделаны существенные выводы о целях и о средствах организации учебного процесса в 
периоды глобальных общемировых кризисов. В одном из своих интервью информационному агентству РБК в апреле 2020 года министр науки и высшего образования Российской Федерации В.Н. Фальков обратил внимание на сложности в работе преподавателей в удаленном формате обучения, касающиеся организации коллективной работы, поддержания внимания студентов, при этом подчеркнул, что сам процесс обучения должен продолжать традиции обычного, т.е. задача преподавателей и в новых условиях «сделать интересным обучение в формате, когда у тебя, по существу, эмоциональные и интеллектуальные моменты идут асинхронно» [1, С. 198; 3]. При этом не следует забывать, что интерактивные форматы в эвристических онтологиях и в онтологии развития волевого усилия должны совмещаться в ориентации психопрофилактического стиля мышления. Соответственно, реализуемый в образовательной системе Российской Федерации компетентностный подход может быть значительно расширен: в него могут быть вложены в качестве некоторых множеств психопрофилактические мероприятия и различные методологические решения профильной направленности на базовом и вариативном уровнях федерального государственного образовательного стандарта [2, С. 32]. Фактически связанные с пандемией коронавирусной инфекции кризисные события в системе российского образования показали, что цифровизация учебного процесса в вузе не сводится только лишь к наличию аппаратного обеспечения и программного обеспечения с удобными и понятными для преподавателей графическими интерфейсами, но что вопрос методологии учебного процесса в цифровую эпоху должен детально прорабатываться в онтологических рамках философской формы мировоззрения.

Речь, безусловно, идёт и об организационно-методологической перестройке мышления самих преподавателей: с началом карантинных мероприятий в период эпидемии коронавирусной инфекции COVID-19 для профессорско-преподавательского состава стал неизбежным выбор инструментов и технологий для запуска изучения дисциплины в дистанционном режиме [8, С. 37], однако образовательные технологии в классическом и в дистанционном образовании отличаются друг от друга и до сих пор не было разработано ни философского обоснования, ни методологической практики каким образом профессорско-преподавательский состав должен совмещать эмоциональные, интеллектуальные и эвристические 
компоненты в дистанционной и смешанной моделях образования. И несмотря на успехи в последнем многие исследователи констатируют факт, что в условиях полного удаленного формата обучения практически невозможна реализация одного из главных постулатов педагогической мысли воспитывающей, формирующей, развивающей и продвигающей роли самого процесса обучения [1, С. 200].

\section{Онтологическое изменение обстановки с организацией учебного процесса в классической и смешанной моделях образования}

Динамика эмоционального и когнитивного развития в дистанционный период обучения в 2020 и в 2021 году не была успешной. Это было вызвано отсутствием проработки алгоритмов и рекомендаций со стороны вышестоящих органов в отношении тех вызовов, перед которыми оказалось современное общество. Негативные стороны дистанционного образования могут быть рассмотрены и детально проанализированы при аппаратно-техническом сопровождении учебного процесса в рамках классической модели образования. Так графические интерфейсы, используемые тинэйджерами и студентами для развлечения и для коммуникации (ТІКТОК, ВКонтакте, Instagram, Telegram) могут стать онтологической основной для построения среды, в рамках которой наиболее успешной будет, как организация учебного процесса в рамках классической модели образования, так и смешанной, и полностью дистанционной. С технической точки зрения эта проблема решается архитекторами программного обеспечения, исследовательский же интерес представляет философское обоснование этого явления. Такие графические интерфейсы как Moodle, Zoom, Google Meet и RealTimeBoard Miro разрабатывались для упрощения жизни обывателей, однако их использование в образовательной среде накладывает отпечаток на организацию учебного процесса в целом. Это касается, в первую очередь, значительной феноменализации мышления обучающихся, фактически отказывающихся от логического способа мышления. На графической схеме выше показана тонкая грань между эвристической характеристикой познания и развлечением (entertainment). Если эвристическая онтология не работает или работает слабо при дистанционном или смешанном типе обучения, частично уместно поднять вопрос о том, чтобы трансформировать учебный процесс в entertainment в чистом виде. Тенденция к этому прослеживается довольно очевидно, когда в 
период пандемии коронавирусной инфекции, вызванной коронавирусом SARSCoV-2, значительным образом снизились показатели психологического состояния [5; 9], как среди тинэйджеров и студентов, так и среди профессорскопреподавательского состава в высших учебных заведениях. Данная проблема может быть разрешена при разработке таких образовательных технологий, которые, с одной стороны, будут формировать экзистенциальный порыв к обучению среди обучающихся, a, с другой стороны, формировать у них довольно ясно осознаваемое волевое переживание. Целесообразно сказать и том, что несмотря на тот факт, что до сих пор не было разработано почти идеального графического интерфейса для реализации образовательных программ, тем не менее в рамках существующих графических интерфейсов [!] теоретически можно реализовывать как эвристические стратегии развития мышления обучающихся, так и укреплять их морально-волевой дух. При этом, имеющиеся методологии ранее обозначенных целей видятся в настоящий момент как рекомендации, которым можно следовать, но и которых можно, без особого труда, не замечать.

\section{Постепенное изменение образовательной среды в классической}

\section{и в дистанционной модели организации учебного процесса}

Современная социально-экономическая ситуация в стране и в системе образования такова, что традиционные формы получения образования и модели обучения не могут удовлетворить потребностей в образовательных услугах, обычно сконцентрированных в больших городах [7, С. 171]. Несмотря на серьёзную критику в адрес дистанционного и смешанного типа обучения, последние могут подвергнуться значительной трансформации. Позволить реализовать это может философская форма мировоззрения в аспекте онтологической концептуализации мышления обучающихся, следующих по пути тех или иных образовательных стандартов. В данный момент подлежат серьёзной проработке интерактивные компоненты при работе с графическими интерфейсами со стороны преподавателей и активность на них со стороны обучающихся. Никакая программа никогда не заменит живого человека, однако эвристизация мышления обучающихся может значительным образом не только снизить феноменальную (перцептивно-ориентированную) замкнутость обучающихся и нивелировать социальную депривацию, если она имеет место быть, но и послужить онтологическим основанием для формирования 
морально-нравственного волевого усилия среди обучающихся. Интерактивное качество обучения может этому способствовать, однако для формирования волевого усилия необходим ещё и формально-логический инструментарий, иногда и минимальный, который только и может подвергнуть концептуализации перцептивно-негативный феноменальный опыт самих обучающихся с их собственной стороны. Это должно осуществляться личностно, а не «nо указке» извне. Графически это выглядит следующим образом (см. рис. 2).

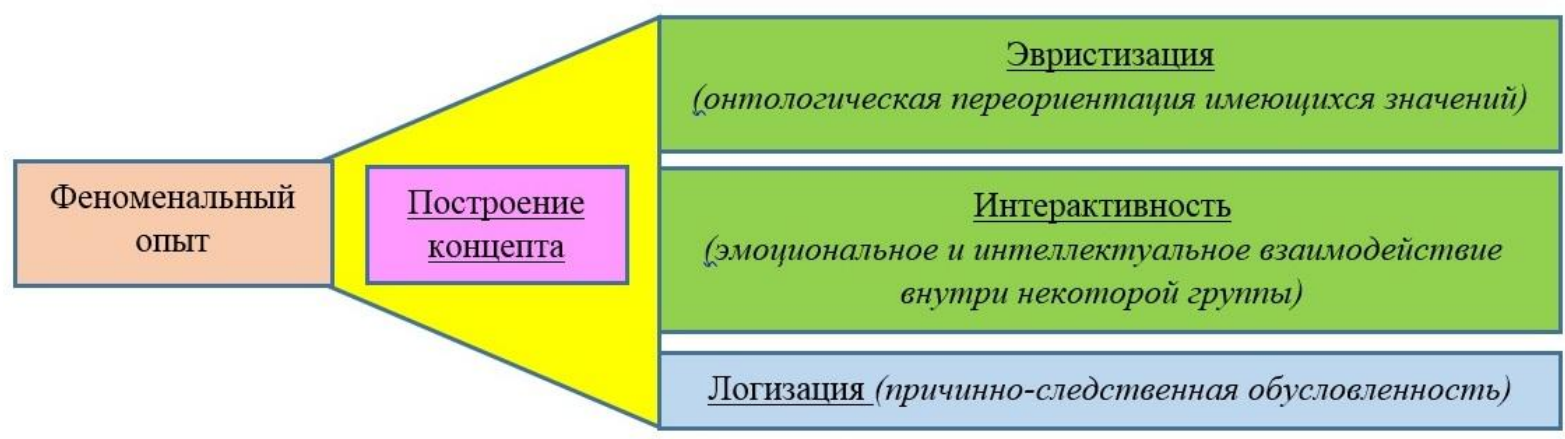

Рисунок 2

В любом случае графические интерфейсы в современном техническом мире, никоим образом, не могут рассматриваться как «абсолютное зло», форматы же цифровизации учебного процесса в нашей стране зависят от качества предоставляемых услуг и если в этих услугах не содержатся компоненты эвристизации мышления обучающихся, которые могут реализовываться как через сложные речевые конструкции (логический компонент), так и через эмоционально-коммуникативное их выражение (интерактивный компонент) сложно будет говорить об онтологических основания цифровых технологий вообще.

\section{Психопрофилактический компонент обучения при цифровом}

сопровождении учебного процесса: феномен ностальгии над прошлым

Психопрофилактические мероприятия могут содержаться в тех образовательных технологиях, которые уже онтологически вложены в читаемые курсы, дескриптивно возможные благодаря утверждённым рабочим программам. Достаточным основанием для организации психопрофилактических мероприятий может выступать герменевтика, понимание которой очевидно в феномене ностальгии. Новалис говорит в одном фрагменте: «Философия есть, собственно, ностальгия, тяга повсюду быть дома» 
[6, С. 86]. Иными словами, у этого понятия есть довольно сложная философская история. Цифровые технологии в некотором отношении упрощают учебный процесс, позволяя более детально познакомиться с экспликацией того или иного материала, однако они же предполагают своего рода примат «феноменального» или «чувственного» над «логическим» или же «имплицитно-выведенным». Нивелировать это позволяет онтологический конструкт ностальгии, поскольку абсолютно любой читаемый курс в рамках учебного плана фактически читается в исторической хронометрии. Т.е. реконструкция опыта предшествующих поколений в аутентичном значении необходима, а так как она составляет научный опыт добавление художественного элемента в экспликацию излагаемого материала способствует более детальному пониманию сущего, если речь идёт о технических дисциплинах и более детальному усвоению того или иного концептуального обобщения, если речь идёт о математике и корпусе социально-гуманитарных дисциплин.

Отметить также следует и то, что информационное проектирование учебной деятельности обучающихся в онтологиях волевого усилия и интертеймента может быть реализовано на практике вне зависимости от качества графических интерфейсов. На настоящий момент последние хоть и требуют качественной программной доработки тем не менее позволяют всё же нивелировать перцептивно-негативные переживания со стороны обучающихся. Это замечание уместно ещё и по той простой причине, что педагогическая база в современной системе образования имеет достаточно фундаментальное онтологическое основание, если говорить о накопленном педагогическом опыте работников этой сферы в Российской Империи и в СССР.

С логической точки зрения наличие психопрофилактического компонента в рамках учебного процесса может быть выражено как когнитивное снятие тех значений культуры (это может быть, как перцептивно-негативный опыт, так и опыт построения продолжительных абстракций, к которым обучающийся может быть не готов формально-логически), которые свидетельствуют об информационной перегруженности их носителей. В герменевтическом смысле это позволяет конфигурировать хронотоп (миросозерцание) обучающихся, если он не соответствует научной картине мира. Термин Aufhebung [когнитивное снятие - прим. авт.] в содержательном плане отражает преодоление субъектом 
границ культуры и возможность занятия им позиции внешнего наблюдателя по отношению к тем или иным феноменам культуры [4, С.17]. Именно с помощью снятия можно подвергнуть значительной нивелировки опыт одного лишь феноменального (чувственного) переживания. Графически это выглядит следующим образом (см. рис. 3).

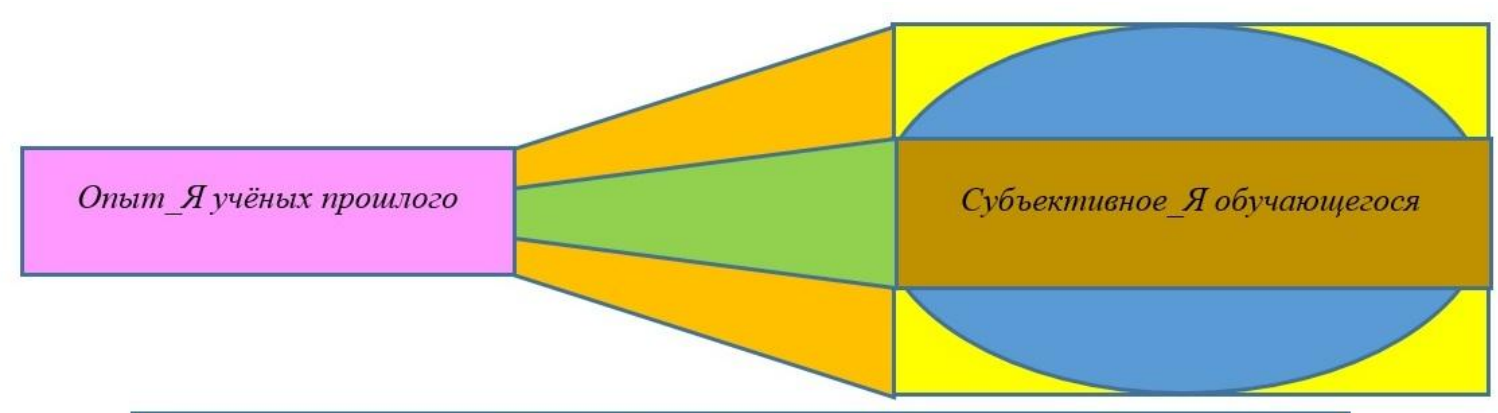

Aufhebung (когнитивное снятие)

обыденного (подчас перцептивно-негативного) и наукоцентричного

Ностальгия как экстраполяция к научному открытию прошлого

Рисунок 3

В дескриптивно-рациональной модели снятие не работает, поскольку гегелевское утверждение-и-отрицание выходит за пределы формальнологического закона непротиворечия в единении одного времени, в то время как при ностальгии как феномене бытия возможно не только когнитивное снятие имеющегося противоречия, но и обозначение двух диаметрально противоречащих картин мира: современно-научной и герменевтическим образом реконструируемой научной картины мира прошлого. В этом отношении уместно заметить, что имеется то достаточное основание, которое позволяет утверждать, что цифровизация современной классической модели образования, исходя из теоретических предпосылок по концептуализации этого феномена, может пройти успешно в условиях современного российского общества.

\section{БИБЛИОГРАФИЧЕСКИЙ СПИСОК}

1. Борзова Т. А. Уроки пандемии: цифровая трансформация высшего образования в формате удаленного обучения // Территория новых возможностей. - Вестник Владивостокского государственного университета экономики и сервиса. 2021. - № 1. - С. 195-208. 
2. Гришин А. А., Алесин И. И., Новикова 3. Н. Перспективы объектноориентированного подхода при создании архитектур организации учебного процесса и психопрофилактических мероприятий в цифровую эпоху // Сборник материалов Всероссийской научно-методической конференции с международным участием. Цифровизация образования: вызовы современности. - Чебоксары: Издательский дом «Среда», 2020. - С. 28-33.

3. Доронов И. Фальков анонсировал появление из-за вируса «другого высшего образования» / Деловой журнал «РБК»: [сайт]. - URL: https: // www.rbc.ru/society/09/04/2020/ 5e8edde 79a79470 aa3b361f7 (дата обращения: 23.12.2020).

4. Константинова Т. В. Модусы нигилизма в культуре транзитивного общества: автореф. дис. ... канд. филос. наук: 24.00.01. - Ростов-на-Дону, 2010. $-24 \mathrm{c}$.

5. Котляров В. Л., Иванов М. В., Козловская Г. В., Кремнева Л. Ф., Калинина М. А., Крылатова Т. А. Синдром изоляции у детей: социальные и клинико-психологические аспекты // Психиатрия и психофармакотерапия. 2020. - T. 22. - № 6. - С.37-41.

6. Хайдеггер М. Что такое метафизика? / Пер. с нем. В. В. Бибихина. М.: Академический проект, 2007. - 303 с.

7. Халиков А. А., Мусамедова К. А., Ибрагимова О. А. Анализ методов дистанционного обучения и внедрения дистанционного обучения в образовательных учреждениях // Вестник научных конференций. - 2017. - № 3 6 (19). - C. 171-173.

8. Шамшурина Е. О., Сазонов С. В. Опыт проведения видеоконференцсвязи в период дистанционного обучения на кафедре гистологии в весеннем семестре 2020-2021 учебного года // Вестник уральского государственного медицинского университета. - 2020. - № 3. - С. 36-39.

9. Юмашев А. В. Психологическая и клиническая патосемиотика пандемии коронавирусной инфекции (SARS-CoV-2): проблемы понимания и поиск корреляций // Азимут научных исследований: педагогика и психология. 2020. - T. 9 - № 2 (31). - С. 380-387. 